\title{
Chapter 9 \\ Racism a Social Determinant of Indigenous Health: Yarning About Cultural Safety and Cultural Competence Strategies to Improve Indigenous Health
}

\author{
Juanita Sherwood and Janine Mohamed
}

\section{Introduction}

This chapter includes a record of the opening session of the first National Centre for Cultural Competence (NCCC) conference held in Australia in 2018 and is a yarn between the two of us. We are both Aboriginal women with qualifications in nursing and are members of Congress of Aboriginal and Torres Strait Islander Nurses and Midwives (CATSINaM). Our respective work in advocating for better health outcomes for our people has been strongly informed by the philosophy and praxis of cultural safety. We have attempted to deal with the legacy of prejudice and racism that remains very active across the health sector in all professions. We have both observed first-hand the impact of how culturally unsafe practice can affect Aboriginal and Torres Strait Islander clients and Aboriginal and Torres Strait Islander health professionals, as well as their families and communities.

\section{Congress of Aboriginal and Torres Strait Islander Nurses and Midwives}

Congress of Aboriginal and Torres Strait Islander Nurses and Midwives is the sole peak body that represents Aboriginal and Torres Strait Islander nurses and midwives along with advocating on the behalf of Aboriginal and Torres Strait Islander peoples'

\footnotetext{
J. Sherwood $(\varangle)$

Faculty of Medicine and Health, The University of Sydney, Sydney, NSW, Australia

e-mail: juanita.sherwood@sydney.edu.au

J. Mohamed

The Lowitja Institute, Carlton, VIC, Australia
}

J. Frawley et al. (eds.), Cultural Competence and the Higher Education Sector, 
health equity. In February 2018, CATSINaM and the Nursing and Midwifery Board of Australia (NMBA) made history by releasing a joint statement on cultural safety and respectful care which included an announcement about developing this principle in the new code of conduct for nurses and code of conduct for midwives (NMBA, 2018). Janine, her team and members were able to make this a reality. She said:

Systemic racism contributes to poor health outcomes experienced by Aboriginal and Torres Strait Islander Australians. By providing health care in a culturally safe and respectful way, and contributing to culturally safe and respectful health systems, nurses and midwives can make a real contribution to health equity for all Australians. (NMBA, 2018)

\section{National Centre for Cultural Competence}

The NCCC was established at The University of Sydney in 2014 and became active in 2015. The centre built its philosophy upon cultural competence from an Indigenous standpoint, with the primary aim of improving the knowledge of all Australians about First Peoples who have cared for and sustained this continent for at least 65,000 years. Cultural competence has been rolled out across The University of Sydney via the development of online modules, workshops and leadership programs, to support the university's aim to educate and graduate their students with the capability of cultural competence.

The University of Sydney took the fundamental step towards addressing cultural competence, as informed by the National Best Practice Framework for Indigenous Cultural Competence in Australian Universities (UA, 2011a), and the guiding principles for developing Indigenous cultural competence in Australian Universities (UA, 2011b). This approach was undertaken to build the skills, attitudes and respectful behaviours among staff and students to develop cultural competence capabilities (Sherwood \& Russell, 2018). The NCCC became the peak body within the university to develop the philosophy to be responsive to its 2016-2020 Strategic Plan and create resources and grow leaders in cultural competence from students, academics and professional staff.

\section{Cultural Safety}

Cultural safety is a strategy for equitable access to health care and health improvement for Aboriginal and Torres Strait Islander peoples. The philosophy and pedagogy were first developed by Māori nurse and scholar Dr. Irahapeti Ramsden. Dr. Ramsden acknowledged that her non-Indigenous peers were very ignorant about how the brutal history of colonisation affected her peoples, and this lack of knowledge impacted on the way they delivered health care to Māori peoples:

The omission of the colonial history of New Zealand in the basic state education system had led to a serious deficit in the knowledge of citizens as to the cause and effect outcomes 
of colonialism. Without a sound knowledge base, it seemed to me that those citizens who became nurses and midwives had little information of substance on which to build their practice among this seriously at-risk group. (Ramsden, 2002, cited in Fredericks \& Best, 2014, p. 53)

This recognition led Dr. Ramsden to recommend decolonisation as a means for nurses to reflect on their bias and lack of knowledge and take personal responsibility for becoming better informed. She also recommended nurses acknowledge the power they hold when working with patients whose worldview of health is not one of mainstream medicine. She defined a three-step process for nurses to provide culturally safe health care for Māori clients:

Cultural awareness is a beginning step towards understanding that there is a difference. Many people undergo courses designed to sensitise them to formal ritual rather than the emotional, social, economic and political context in which people exist.

Cultural sensitivity alerts students to the legitimacy of difference and begins a process of self-exploration as the powerful bearers of their own life experience and realities and the effect this may have on others.

Cultural safety is an outcome of nursing and midwifery education that enables safe service defined by those who receive the service. (Ramsden, 2002, cited in Fredericks \& Best, 2014, p. 54)

In 2005, the Nursing Council of New Zealand prepared and released a summary of the five principles that underpin cultural safety for nurses and midwives:

Reflect on your own practice; seek to minimise power differentials; engage in discourse with the client; undertake a process of decolonisation; ensure that you do not diminish, demean or disempower others through your action. (Fredricks \& Best, 2014, pp. 64-68)

In 2011, they released this definition of cultural safety:

the effective nursing practice of a person or family from another culture and is determined by that person or family. Culture includes, but is not restricted to, age or generation; gender; sexual orientation; occupation and socioeconomic status; ethnic origin or migrant experience; religious or spiritual belief; and disability. The nurse delivering the nursing service will have undertaken a process of reflection on his or her own cultural identity and will recognise the impact that his or her personal culture has on his or her professional practice. Unsafe cultural practice comprises any action, which diminishes, demeans or disempowers the cultural identity and well-being of an individual. (Taylor \& Guerin, 2014, p. 11)

Nursing has led the way in Australia and New Zealand in embarking on cultural safety philosophy and practices. The decolonising agenda is a critical strategy that is required among both health professionals and the systems they work within.

\section{Cultural Competence}

Cultural competence is a strategy that was developed in the late 1980s in the United States of America (US) aimed at providing equitable health care to those who have 
been marginalised - namely, First Nations peoples, Hispanic and African Americans, and other disadvantaged socioeconomic groups. The focus of this strategic approach is on the embedding of cultural change within a health system. It articulates clearly that this requires the training of staff, specific policy development, and assessment of the effective uptake by health professionals. This definition is recognised internationally and, particularly, in population groups whose cultural diversity is different to that of their health professionals, and who are often treated poorly because of this difference.

The National Center for Cultural Competence in Washington DC, United States of America (US), developed the following five elements to support organisations and their systems to direct the uptake of cultural competence.

1. Value diversity,

2. Be able to conduct cultural self-assessment,

3. Be conscious of the dynamics of cultural difference,

4. Acquire and institutionalise cultural knowledge,

5. Adapt services to reflect and understand cultural diversity in the community. (National Center for Cultural Competence, US, n.d.).

The elements also need to be taken up in a congruent manner to assist the shifting of cultural naivety towards an openness to cultural diversity.

\section{Yarning}

We use a yarning methodology as this is an Indigenous mode of sharing and delivering knowledges and experiences that reflects and respects our worldviews and ways of knowing, being and doing business, and reciprocity. Indigenous Academic Karen Martin affirms this standpoint: "telling stories is part of Indigenous pedagogy and an established methodology in passing on information; as Indigenous people we have all grown up listening and learning from stories" (Martin, cited in Bessarab, 2010, p. 39).

Our aim, in our yarn, is to pass on our stories in an informal manner, drawing on our work experiences and the wisdom of others who have worked with us over a number of decades. Cultural safety as a strategy for equitable access to health care and health improvement has driven both of our personal aspirations in making a positive impact to the health and wellbeing of our peoples. 


\section{The Yarn Begins}

\section{Janine}

When did you first hear that term, cultural safety?

\section{Juanita}

I first heard it at the CATSIN conference. It was in Queensland, and it was Irahapeti Ramsden speaking at our conference, and we sat there and listened to this amazing Maori nurse who talked to us about the importance of cultural safety and the fights that she had and continued to be having in New Zealand. She showed us that the New Zealand press had created a cartoon used to portray her, and it was-it was meant to be a caricature of a 'noble savage'. A very discriminatory portrait of a male with a bone in their hair and in their nose, chained up in a hospital bed.

Ramsden's attempt to bring about cultural safety, received much criticisms. This was and is because racism remains richly embedded in New Zealand and Australia, we knew this was going to be a battle to get this strategy happening, but we were all there as First Nation nurses to support our sister in New Zealand and here.

\section{Janine}

A bit of a back story. I'm from Point Pearce Mission in South Australia. When I went to the big smoke to finally do my nursing degree, I was fairly naïve, to say the least. And nursing had just introduced this concept of cultural safety and I was at Flinders University at the time talking to the Head of School, and she declared herself as a Pākehā woman. I looked at her and I thought: I wonder where that mob comes from?

Not knowing that that's what New Zealanders called their whitefellas. So, I was sitting there quite wide eyed at this woman. She had her shoes off. She was walking and her palatial suite, with her arms flinging around in the area and talking about cultural safety.

So, to put it mildly, she could've been speaking a foreign language to me at the time. I couldn't understand the constructs that she was talking to me about, let alone racism, to understand racism at that point in my life was literally just a feeling that I encountered.

When someone expressed racial bias towards me, I felt shame, or I felt like I wanted to run and hide. So, I suppose the gem learning from that was later on I really acknowledged that just because you're a black fella you don't need to understand the terminology around racism or that you understand what cultural safety is. 
My head of school gave me a whole load of readings and I went away. I read them, and it was just these constant 'aha' moments. What I described it as was learning about white fellas, their power, their privilege and where that placed me and how their attitudes were formed. So, it gave me a really interesting moment that I now get to reflect on and remember, but at the time it was quite funny the way it all came to fruition.

And I think there's a big issue around when we do talk about cultural safety, there's a lot of misunderstanding about what are we talking about.

\section{Juanita}

And when we're talking about cultural safety or we're talking about cultural competence and I'd like to just say that they basically mean the same, competence is about a system, but cultural safety is individualised treatment and patient-centred care. And cultural safety, cultural competence, cultural proficiency, and there's many other terms. I feel, often we get lost in being too simplistic about the terminology, and what we really are thinking about is ensuring that our people are safe in the health care settings.

People have choice and people have control over those choices, so they had a sense of control of what they're having in their health treatment, and they have a sense of being safe in that space. And I guess-respected in that space.

My learnings of cultural safety came post my experiences of a lot of institutionalised racism in the health care settings, and my first research experience which I really tackled naively, but I'm glad I did. Working in Redfern as a child and family health nurse where hearing loss was an issue that really impacted on children's learning abilities and was not being addressed. Many of the inner-city schools had really high rates of otitis media, which is a middle ear disease which many children get, and often, they're treated with antibiotics very quickly, and they recover. But in our communities, that wasn't happening. People had had otitis media for a long time, and it had a big impact on their hearing and ability to learn to listen.

If you don't learn to listen between the zero to three years of age group, you're going to have trouble at school. This issue was raised within the community health centre. I was told, "Oh, that's not a problem. We don't really worry about that." And I went, "Oh, yes we do." That was my first opportunity of working in community, talking to community about, hey, we've got to do something about this. It's not OK. I know this is not OK. I know I've just learned in teaching that a hearing loss is a problem. And we went to Menzies School of Health Research and we brought in a researcher who showed us how to do some research.

A very famous nurse Jennifer Bush, Alison Bush's twin sister worked on this project with me. We ran a community research project where we screened a hundred children within the Redfern area. Eighty-six percent of them had an educationally significant hearing loss. Really appalling. And with that information, at the time, Linda Burney was the President of the New South Wales Aboriginal Education 
Consultative Group, part of our community grouping, and she took it up with the Minister for Education, and the Minister for Education said, "Right. We're going to do something about this."

And immediately, we had teachers for kids with conductive hearing loss. Before it was just kids who had sensorineural hearing loss, but conductive hearing loss is just as significant, but it had been ignored even by Ear Nose and Throat Specialists (ENTS). A load of ENTS I worked with along this line said, "Why don't we get this?" And I said, "I don't know. I don't understand why you didn't realise if you can't hear, you can't learn", but they didn't.

But they were open to listening. And they did hear-some didn't, of course, but many did hear, and they chose to work with us, which was great, and we did make a difference, and 10 years later, with the ear, nose and throat clinics in all our Aboriginal Medical Services (AMS) across the country. We made a difference, because we didn't-well, we rejected the institutional conceptualisation of, well, that's just the way it's going to be.

That story reminds me of an advertisement that's related to one of our guests in the room, Dr Chelsea Bond, where the Queensland Education Department put a call out for Aboriginal teachers to go and work in Aboriginal and Torres Strait Islander communities. It was some sort of selling point by a teacher that basically said she loved working with naughty misfits with a whole heap of Aboriginal kids around here, true deficit ideology. So that's the pervasive messaging that's out there, and so it's easier for our kids to be naughty or to be misfits than it is for them to actually not be-having access to good health care. And I think that's something that we've looked at for a while and people have been-well, I talk about it a lot-about problematising us in relation to creating-you know, we are a problem because we're not hearing. Well, there is that problem.

But flip it, this is what we've been talking about at the university, is we're the problem, that we don't recognise that we have to provide care to children with hearing loss, and to children with visual loss, with speech issues. We need to be providing care to all children, not the twenty percent that have perfect vision, hearing and speech. And I think that's what we've naively considered that we are treating everyone the same and when we treat everyone the same, we actually create minorities. We create the issues.

But sometimes people haven't been treated the same and I suspect that's probably our biggest issue in Aboriginal health, is the lack of access to respectful, culturally safe health care.

\section{Janine}

We do hear that as health professionals we apply a cookie cutter approach. A health professional will say with pride, "I treat everyone the same", but that gives us the notion that there's equality and that doesn't create equity. Equity is about giving people what they need and acknowledging that we don't all start from the same place 
and therefore we need to see difference and respond to difference respectfully by giving people what they need.

But going back to your comment before about cultural safety versus cultural competence, I love this quote by Dr. Gregory Phillips who basically said it in a nutshell, which is it doesn't really matter what philosophies we're talking about, it's actually that our mob get treated with respect and care and the best-quality care.

So, we certainly talk about cultural safety at my organisation. It does come from Dr Ramsden's Indigenous nursing philosophy, we honour Indigenous knowledges and we honour that she was an Indigenous nurse. I think there was a misnomer with the title of cultural competence, in that there seems to be an epiphany that you can reach and become competent, whereas this work is a lifelong journey.

\section{Juanita}

Absolutely and I think from the national centre's perspective, we've always said that this is a journey and it's a lifelong journey, you never make it, and it's really critical to tell people that, you know, no matter which community you walk into, there's such diversity. You will never know how to ensure that you work safely, and we often-I guess working in the academy, I've found people are very scared to put their hands up to say, "I don't know". It's something that people are fearful of, because this is the space where you're meant to know it all. And, in fact, the healthiest thing for you to ever do is to say is, "I don't know and I'd like to learn and I'd like to listen and I'd like to hear and how can I be more helpful in this space?".

We often don't appreciate that that's what we need to do as soon as we walk into any space, a health setting, an education setting, and particularly working in communities, our communities, and other communities.

\section{Janine}

So, one of the things that happens for us at our organisation, we're an organisation of five staff, and we take care of around 2000 Aboriginal and Torres Strait Islander nurses and midwives and we advocate to many stakeholders on the recruitment and retention issues that they face. Probably the larger part of our work is ensuring a culturally safe health system and ensuring that people demonstrate cultural safety, and therefore, we experience better health outcomes for our people. 


\section{Juanita}

We seem to be the people that are pushing the agenda, and I agree, we have been doing this for a long time. This has been an agenda that-it's critical. If you want good health care, you want great education, you want anything, you need to actually appreciate that we have to be working with diverse areas.

First, though what's probably the most critical thing, is that Australia needs to know that it is occupying sovereign lands of Aboriginal people, and Torres Strait Islander people, and we have not been given any practices to deal with the problems this has caused. There is a lot of healing to happen.

There's still a lot of recognition of issues, and not that cultural safety is about, you know, "you must understand this", but you must appreciate, I guess, the public health agenda, which is, you know, racism causes health inequities. Colonisation and its policies created dramatic health issues. And they've been sustained through colonial policy. They have not ceased.

We will be talking about grandmothers against removals who are still, you know, talking about-we've got years and generations of people still being removed, and the numbers are increasing every year, and this is something we do have to recognise is part of a legacy of the ongoing colonial strategy of knowing what's best for us First Nations Peoples.

\section{Janine}

For us, we often talk to non-Indigenous lecturers in this space and support their work. We also talk to many organisations who have interest in this space and want to take leadership in the implementation of cultural safety. Often people don't realise that cultural safety, is a concept is good for everyone. When you were talking about diversity and joining with diverse groups, absolutely.

\section{Juanita}

We know that such ghastly health rates are part of not necessarily poor health care, but it's been the lack of access to care. There's been so many people who've not been able to have the care that they thought everyone should deserve. When you talk about access to health care, most people's brains jump to Central Australia, geographically not having access to health care, but we are talking about Western Sydney where most of our mob live. 


\section{Janine}

So, access to health care, I'll just give you an interesting conversation that we often have with nurses and midwives, which is to start to talk about cultural safety and we say, "Do you often ask people if they're Aboriginal or Torres Strait Islander?", to which some nurses, midwives might reply, "Not if they don't look it."

So, we do anatomy and physiology in nursing; there's nothing in there that prescribes what an Aboriginal people looks like? Therefore, people are drawing upon the sensationalism of media about what we as a group look like. Often people will say they don't ask the question because they ... "don't want to offend someone." So, we begin to uncover some of the biases-well, the racial bias that people have been fed about what an Aboriginal person looks like and I suppose, that it is shameful to be Aboriginal. And we recently went to a conference and a non-Indigenous student was on a panel with me, and he was saying "I don't know why I ever had to learn cultural safety." Any of you that are in the room that are lecturers would have experienced that first-year students in your Aboriginal cultural safety course impart a fair bit of resistance in learning this topic.

The young person on the panel then went on to state that, "I'm never going to see an Aboriginal person so why I have to learn this stuff?" I took a couple of moments to think about it and I replied to him, "How do you know when you see Aboriginal people? What do they look like?" We unpacked that label and I said to him, "Do you know how important it is for those Aboriginal students sitting in that classroom to actually hear something of themselves, to actually hear about their own people, not that - that we're something in a museum that's a dusty old culture, that we're a vibrant culture and resilient today."

\section{Juanita}

I think that's critical to why we really want to hit it at university and why we think it needs to be broadened across the curriculum beyond-health is vital but we've got to be thinking engineering. We've got to be thinking physics. We've got to be thinking every area.

We want every Indigenous person that walks into all universities, not just Sydney, to feel safe enough to be and exist as an Aboriginal person in that classroom, not to be told that I don't need to learn about Aboriginal issues because, you know, they're irrelevant to me. And I think, you know, learning about Aboriginal issues is very relevant to all Australians, because we are the First Peoples of Australia and if you don't understand and appreciate and respect that, then you don't respect yourselves.

That's probably the most important thing around cultural competence and cultural safety; not that it just improves the way you work with others, it actually opens your space and improves your own life. It actually enables you to consider the world from a point of view that is less about the media's perspectives, it's less about your 
grandmother's perspective, it's about what you've learnt to learn, and I think that's what we really do target in cultural competence-unpacking your biases, unpacking how you developed your opinions.

Opinions aren't knowledge. How do we build our evidence around what is what we want people to grow and develop knowledge in? There's always that notion between what's cultural awareness versus cultural safety. And I'll say to people: if you don't get uncomfortable, you weren't in cultural safety training and if you weren't learning about, you know, things like white privilege, critical race theory, racism, you weren't in cultural safety training.

\section{Janine}

My organisation (CATSINaM) did a great deal of work together with the NMBA, the Australian Health Practitioner Regulation Agency (AHRPA), ${ }^{1}$ Australian College of Nursing and Australian College of Midwives regarding the systemic embedding of cultural safety. Ultimately, we collectively decided to add cultural safety to the codes of conduct for nursing and midwifery and put this idea out for public consultation. You had the opportunity to do individual submissions, go to workshops. There was not one submission that spoke out against cultural safety in the codes. And I should also mention that it was in there for the first time, cultural safety was to be embedded, but it was also the first inclusion for bullying and harassment. By adding these new elements to the codes, we weren't calling people bullies or saying that, nurses harass people; nor were they saying that nurses and midwives were racist. The codes are about what we want to hold our professions accountable to, and what we don't accept. And, really, it comes down-and I guess working in the health field, it is basic occupational health and safety, and it's about ensuring that we do look after people securely. I guess I've had an amazing health experience.

\section{Juanita}

My appreciating of ensuring our patients felt safe came from my experience of my time at St Vincent's in 1984. This is when we discovered we had AIDS in Australia. And that was a massively scary time for everybody, because they did not know how AIDS was transferred. Many staff at St. Vincent's, walked out of the hospital, as they were too terrified that they were at risk of catching AIDS.

I was working and running a number of wards a shift, because we had lost so many health staff. This really ignited in me how we-well, how the few of us that were left in that setting, that year about how important it was to make sure that we made

\footnotetext{
${ }^{1}$ The enactment of the Health Practitioner National Law Act 2009 resulted in the replacement of the pre-existing 85 State and Territory Boards with 14 National Boards, of which one is Dental.
} 
our patients feel that they were valued and that was cared for and safe. These were young men who were dying of a dreadful disease. We'd just sort of discovered what it was. We only just realised how we had to treat this, and I guess-and what came out of that space was critically some important issues around infection control, things that were about knowledge changes and behaviour changes. I was thinking, "That's exactly what we're asking for with cultural safety." It's not something hard. We do have to change behaviours in this space because we are going to make a difference and we save lives doing this.

Cultural safety also plays a significant role in academic rollout. At the NCCC, our aim is to ensure our Indigenous students and staff are culturally safe to share their perspectives, their histories, their experiences within an institution that mostly promotes a western doctrine that fails to respect or acknowledge other ways of knowing, being and doing. Our presence in these institutions does require support as we still are dealing with the unbalanced histories of our country in the classrooms we share with our peers and colleagues.

I guess it's about taking the brave steps, and this university has established the national centre and saying that this is a priority and following Universities Australia's 2011 statement on trying to, you know, improve outcomes for Indigenous studentsthat has been a big step. It's about, I guess, how do we build it into the curriculum? How do we get it embedded into spaces where people feel comfortable? And again, I think it's just like-I want to take it back to infection control, you know. We knew that we were killing people because we weren't washing our hands. We learnt that if we didn't wear a mask, we could cause problems, and we had to change behaviours. We had to put needles in yellow bins. We had to do a whole lot of different health care approaches. We had to learn about it. We have had to build our knowledge, and we need to spend some time building knowledge around why cultural safety or cultural competence is important, and getting people to participate in that space.

We have found that the work that we have been doing in our cultural competence leadership programs has been very rewarding for myself and the people who participate in it and I think that people get an opportunity to have an opportunity to talk about it, and you need to give people the space to have time to talk, explore, and do something about it.

\section{Janine}

First and foremost, it's not up to Aboriginal people to be doing this week, I'll reiterate that it takes leadership, commitment, long term. Like I said before, if you walk into your first-year class of nursing and midwifery on Aboriginal and Torres Strait Islander health culture and history, and Gregory Phillips has covered this phenomenon in his Ph.D., if you were to take the feedback forms just from that first term, due to the poor reviews you would never run that course again. So, it takes bravery and leadership to actually do this work in universities and to embed it in institutions. 
And I'll also say that with the nursing and midwifery codes, we were really naive, I think, we should have looked and learned for the New Zealand experience where Dr. Ramsden endured much backlash from the government and the professions. I was amazed that my non-Indigenous colleagues were so surprised at the backlash in the media. As Aboriginal people, we know that this happens. We know we're going to get pushed back, especially when we're on the right track and we're pushing the right button.

It's about building it into systems. It's about leadership. It's also about once it's in that system, so it's in your accreditation framework, then you've got the assessors coming in and assessing you and they've never done cultural safety before in their life. How do they actually know that you're delivering quality staff? It's the support of your Indigenous and non-Indigenous staff, non-Indigenous people step into space and they get professional paralysis. I think it's about bringing them together and building their capacity to be able to work with us in this space and be true allies.

It's probably about outcomes as well. How do we measure it? Some of the universities that have done some really great work which Juanita was involved in which was student attributes. Then they get into the hospital system, and this is where cultural safety tells us that it can't be just individuals, it has to be a system approach, because if you are an individual operating in a system that is not culturally safe. That is, the policies aren't geared and thought about for Aboriginal people, you are enacting racist policies because you've shut Aboriginal people out of that. That's why I keep saying it has to be a pipeline systematic approach to how we embed this, then how we assess it and how we measure the outcomes.

Australia does a really great job at reconciliation. Australia, they talk about race relations, so I'll give you a titbit from their barometer. It says that when asked, Indigenous people trust non-Indigenous people more than non-Indigenous people trust us. That's a really good barometer about what is happening in our health systems, so we have to be able to measure that cultural safety is working, because we have to prove it, and have that academic discourse in Australia.

\section{Juanita}

But I guess providing a culturally safe space is not just a physical place, and I think sometimes we've been stuck in thinking it's going to be a building or it requires having people who are around you who have respect for your ways of knowing and being and doing, who aren't going to challenge you just for being who you are-and we have to build that philosophical space so that we can have that safe place.

And I think that's what cultural competence engenders, but we need it to work systemically, and as Janine has said, if I don't practise cultural safety in a system that isn't culturally safe, you're going to be harmed-if I practice. And so, we have to make sure that the system works with us as we promote this cultural safety approach.

So, ideally this whole university and every university should be a safe space and we need to grow that through developing a better way of knowing in the space. I just 
think that what has been achieved in nursing and midwifery suggests that we have actually had a big leap in thinking, and the backlash from another minority group has been sensational, but there's been really good critique and I think, if anything, that's been a good public service. I think we've moved and made a difference.

Having been able to work in the tertiary education system for a long time, at the last couple of universities I've been able to get cultural attributes assessments a happening thing, that is change. Getting cultural safety criteria into the curriculum, which students are being examined on, is change. This is critical. We have made a difference. We have moved on.

We may not be where we'd all like to be, but as Janine has said, you know, it took two hundred years to get here. And learning around culture, and I guess perhaps going back to what our Vice-Chancellor said, we are learning a lot about the world. We are learning that we need to know more than just what we know. We need to learn around how we value, we need to learn what wellbeing means. We need to learn a whole lot of ways of doing business.

I have to believe that we're on the journey, or else it becomes too disheartening. Australia needs to learn a lot more about its culture and its discourse around critical race theory. We have come some way and it's been good. It begins a nation discussing instead of sweeping it under the carpet. I wish we had a few more of our voices out there, but hopefully, after today, we will.

\section{Conclusion}

To open the NCCC conference, we used a yarning methodology because it is an Indigenous mode of sharing and delivering knowledge and experiences that reflect and respect our worldviews and ways of knowing, being and doing business, and reciprocity. We shared our stories and experiences of working to promote health equity, to address racism in health systems, and to embed cultural safety across a range of settings. We also discussed the difference between the philosophy and praxis of cultural safety and cultural competence. We stressed the importance of health practitioners acknowledging their need to learn as a lifelong process, and of asking questions such as, "I don't know and I'd like to learn and I'd like to listen and I'd like to hear, and how can I be more helpful in this space?" From our yarn, a number of conclusions can be made:

1. Colonisation and its policies created dramatic health issues, and they've been sustained through colonial policy and structures. They have not ceased.

2. Racism causes health inequities. We need to be identifying and understanding racism in the broader social context, in media stereotyping and the institutional/health care setting.

3. Cultural safety means Aboriginal people feel respected, and power dynamics are acknowledged and addressed. One outcome of cultural safety is that people express that they feel they have control over the design, development and delivery 
of health services; they experience choices; they have a sense of control over their health treatment; and their human rights are acknowledged and respected.

4. Poor health outcomes are not necessarily due to poor health care: it's been the lack of access to care that is the problem.

5. We are treating everyone the same and when we treat everyone the same, we are not acknowledging that people do not all start from the same level of privilege, therefore we are not acknowledging what people need individually and this creates unfairness and poor health outcomes for minorities. We create these issues.

6. The healthiest thing for you to ever do is to say is, "I don't know, and I'd like to learn, and I'd like to listen, and I'd like to hear, and how can I be more helpful in this space?" We often don't appreciate that that's what we need to do as soon as we walk into any space whether it's a health setting or an education setting and, particularly, when we're working in communities-our communities, and other communities.

7. We want every Indigenous person that walks into all universities, not just Sydney, to feel safe enough to be and exist as an Aboriginal person in that classroom.

8. There's always that notion of what is cultural awareness versus what is cultural safety. If you don't get uncomfortable, you weren't in cultural safety training and if you weren't learning about white privilege, critical race theory and racism, you weren't in cultural safety training.

\section{References}

Behrendt, L., Larkin, S., Griew, R., \& Kelly, P. (2012). Review of higher education access and outcomes for Aboriginal and Torres Strait Islander people: Final report. Canberra: Department of Industry, Innovation, Science, Research and Tertiary Education.

Bessarab, D., \& Ngabdu, B. (2010). Yarning about yarning as a legitimate method in Indigenous research. International Journal of Critical Indigenous Studies, 3(1), 37-50.

Cross, T. L., Bazron, B. J., Dennis, K. W., \& Isaacs, M. R. (1989). Towards a culturally competent system of care: A monograph on effective services for minority children who are severely emotionally disturbed. Washington, DC: Child and Adolescent Service System Program Technical Assistance Center, Georgetown University Child Development Center.

Fredericks, B., \& Best, O. (2014). Yatdjuligin: Aboriginal and Torres Strait Islander nursing and midwifery care. Port Melbourne, VIC: Cambridge University Press.

National Centre for Cultural Competence. (2016). Conceptual frameworks/models, guiding values and principles. Retrieved from https://sydney.edu.au/nccc/.

National Center for Cultural Competence, USA. (n.d.). Foundations. Retrieved from https://nccc. georgetown.edu/foundations/framework.php.

Nursing and Midwifery Board of Australia. (2018). NMBA and CATSINaM release joint statement on culturally safe care. Retrieved from https://www.nursingmidwiferyboard.gov.au/News/201802-01-nmba-catsinam.aspx.

Sherwood, J., \& Russell, G. (2018). How we do business: Setting the agenda for cultural competence at The University of Sydney. In J. Frawley, S. Larkin, \& J. A. Smith (Eds.), Indigenous pathways, transitions and participation in Higher Education: From policy to practice. Singapore: Springer Open. 
Taylor, K., \& Guerin, P. (2014). Health care and indigenous Australians: Cultural safety in practice. South Yarra, VIC: Palgrave Macmillan.

Universities Australia. (2011a). National best practice framework for Indigenous cultural competency in Australian Universities. Canberra: Universities Australia.

Universities Australia. (2011b). Guiding principles for developing Indigenous cultural competency in Australian Universities. Canberra: Universities Australia.

Juanita Sherwood is a Wiradjuri woman from New South Wales. She has over 25 years of experience in Indigenous health and education, community-based research methodologies, and decolonisation strategies that improve health and healing outcomes for Indigenous people. She is currently the Associate Dean (Indigenous) for the Faculty of Medicine and Health at The University of Sydney.

Janine Mohamed is a Nurrungga Kaurna woman from Point Pearce in South Australia. She has over 25 years' experience in nursing, management, health workforce, health policy, and project management in the Aboriginal and Torres Strait Islander health sector. Janine is currently the CEO of the Lowitja Institute.

Open Access This chapter is licensed under the terms of the Creative Commons Attribution 4.0 International License (http://creativecommons.org/licenses/by/4.0/), which permits use, sharing, adaptation, distribution and reproduction in any medium or format, as long as you give appropriate credit to the original author(s) and the source, provide a link to the Creative Commons license and indicate if changes were made.

The images or other third party material in this chapter are included in the chapter's Creative Commons license, unless indicated otherwise in a credit line to the material. If material is not included in the chapter's Creative Commons license and your intended use is not permitted by statutory regulation or exceeds the permitted use, you will need to obtain permission directly from the copyright holder.

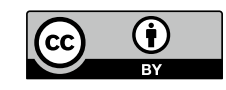

